\title{
MEMBUAT SEPEDA AIR PIPA PVC PADA BUMDES SITU RANCABUNAR DESA BOJONGMENGGER, KECAMATAN CIJEUNGJING KABUPATEN CIAMIS
}

\section{MAKING A PVC PIPE WATER BIKE IN BUMDES OF RANCABUNAR LAKE, BOJONGMENGGER VILLAGE, CIJEUNGJING DISTRICT CIAMIS REGENCY}

\author{
Zenal Abidin, Mujaddid Faruk* \\ Universitas Galuh Ciamis \\ Jl. RE. Martadinata N0. 150 Ciamis \\ *Email: mumumujaddid@gmail.com
}

(Diterima 26-11-2020; Disetujui 18-02-2021)

\begin{abstract}
ABSTRAK
Program PKMS yang dikemas dalam kegiatan "Membuat Sepeda Air Pipa PVC pada BUMDES Situ Rancabunar Desa Bojongmengger, Kecamatan Cijeungjing Kabupaten Ciamis”, bertujuan untuk mengatasi masalah kurangnya sarana pendukung wisata Situ Rancabunar. Metode yang digunakan dalam melaksanakan program pengabdian ini yaitu metode instruksional, diikuti dengan praktek yang meliputi lima tahapan, yaitu: 1) Penyampaian informasi (sosialisasi/penyuluhan), 2) Pelatihan keterampilan membuat sepeda air pipa PVC yang meliputi: percontohan pembuatan sepeda air, percontohan penggunaan sepeda air untuk para petugas dan pengunjung, 3) Manajemen dan promosi wisata melalui leaflet, poster, dan media sosial, 5) Seminar hasil kegiatan pengabdian. Partisipasi mitra dalam mendukung program ini, selain sebagai peserta dalam pelatihan dan pelaksana program, juga ikut sharing dalam penyediaan alat dan bahan pembuatan sarana sepeda air. Selain itu, kader yang telah dilatih mempunyai tugas untuk mengembangkan, dan menularkan kepada masyarakat di sekitar BUMDES. Hasil yang dicapai, pengelola BUMDES mendapatkan pengetahuan tentang pembuatan sarana wisata, dan manajemen serta penataan sarana wisata, dan masyarakat sekitar Situ Rancabunar mendapat tambahan sumber pendapatan dengan keberadaan sepeda air ini.
\end{abstract}

Kata kunci: Sepeda, air, pipa, PVC

\section{ABSTRACT}

The PKMS program, which is packaged in the activity "Making PVC Pipe Water Bikes at BUMDES Rancabunar Lake, Bojongmengger Village, Cijeungjing Subdistrict, Ciamis Regency", aims to overcome the problem of lack of supporting facilities for Situ Rancabunar tourism. The method used in carrying out this service program is the instructional method, followed by practice which includes five stages, namely: 1) Submission of information (outreach/counseling), 2) Training on skills to make PVC pipe water bikes which include: pilot making of water bikes, piloting use of water bikes for officers and visitors, 3) Management and promotion of tourism through leaflets, posters and social media, 5) Seminar on the results of community service activities. Participation of partners in supporting this program, apart from being participants in training and program implementers, also sharing in the provision of tools and materials for making water bikes. In addition, cadres who have been trained have the duty to develop and transmit to the community around the BUMDES. The results achieved, BUMDES managers gain knowledge about the manufacture of tourist facilities, and management and arrangement of tourist facilities, and the community around Situ Rancabunar gets additional sources of income with the existence of this water bike.

Key words: Bicycle, water, pipe, PVC

\section{PENDAHULUAN}

Situ Rancabunar merupakan danau alam (embung desa) yang status kepemilikannya adalah tanah carik Desa Bojongmengger, Kecamatan Cijeungjing Kabupaten Ciamis, danau seluas 3 hektar tersebut belum dimanfaatkan secara optimal, 
Membuat Sepeda Air Pipa Pvc Pada Bumdes Situ Rancabunar Desa Bojongmengger, Kecamatan Cijeungjing Kabupaten Ciamis

Zenal Abidin, Mujaddid Faruk

padahal lokasinya strategis yang hanya berjarak $10 \mathrm{~km}$ sebelah timur kota Ciamis, dan berada hanya $20 \mathrm{~m}$ dari jalan nasional 3 jalur selatan Jawa tepat di belakang balai Desa Bojongmengger Kecamatan Cijeungjing Kabupaten Ciamis. Selama ini masyarakat sekitar hanya menggunakannya sebagai cadangan air dan tempat rekreasi di hari libur seperti jogging dan memancing, yang kondisinya kurang terrawat serta sebagian tertutup eceng gondok.

Pemerintah Desa Bojongmengger mempercayakan pengelolaannya kepada Badan Usaha Milik Desa (BUMDES) Desa Bojongmengger dan belum dikelola secara optimal, padahal tempat tersebut potensial digunakan sebagai objek wisata alam terutama wisata air. Menurut Bakri (2012), sektor pariwisata merupakan industri kreatif yang potensial dikembangkan di Indonesia. Selain menjanjikan dan dapat dikembangkan dengan cepat, bisnis ini merupakan usaha padat karya yang bisa bersinergi dengan banyak sektor usaha lain, dan untuk menatanya perlu kreatifitas tinggi, inovasi dan terobosan terutama oleh para pelaku usaha.

Keberadaan objek wisata air Situ Rancabunar juga diharapkan dapat mengurangi jumlah pengangguran, dan meningkatkan pendapatan masyarakat desa Bojongmengger. Menurut Yoety (2012), objek wisata dapat dijadikan sebagai katalisator dalam pembangunan. Selain dapat meningkatkan pemerataan pendapatan, meningkatkan kesempatan kerja, penerimaan pajak, meningkatkan pendapatan nasional, sekaligus dapat memperkuat posisi neraca pembayaran.

Situ Rancabunar merupakan aset kekayaan Desa Bojongmengger yang masih membutuhkan berbagai upaya untuk pemberdayaannya. Menurut Maharani (2014), pariwisata di daerah-daerah sangatlah banyak bila mampu memanfaatkan potensipotensi yang ada, pemerintah dan masyarakat daerah saling membantu dalam pengembangannya tersebut sehingga akan mengangkat segi ekonomi, budaya dan pendidikan daerah itu. Pariwisata sangatlah mampu dalam mengatasi masalah kesejahteraan bila dikembangkan secara profesional.

Pembukaan objek wisata baru Situ Rancabunar ini sejalan dengan prioritas pemerintah dalam pengembangan nasional. Menurut Ghani (2017), pemerintah saat ini telah menetapkan beberapa program prioritas pengembangan nasional. Pengembangan program prioritas tersebut ada 18 (delapan belas) program yang salah satunya adalah pariwisata. Menurut Ginting (2016), motivasi wisatawan nusantara Indonesia untuk berwisata semakin tinggi. 
Salah satu alternatif pemanfaatan Situ Rancabunar sebagai BUMDES adalah dengan membuat sarana pendukung wisata berupa sepeda air pipa PVC.

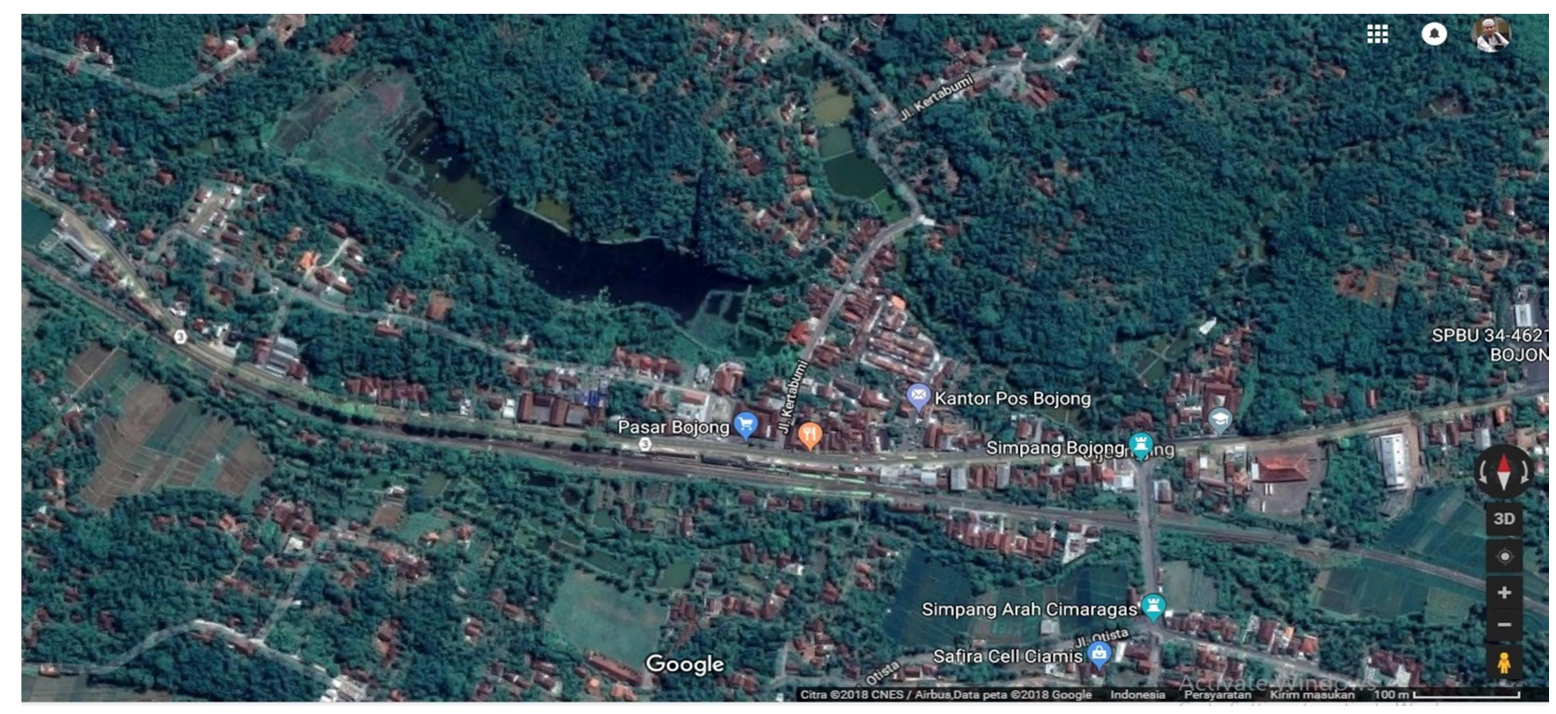

Gambar 1. Peta Lokasi Situ Rancabunar dan BUMDES Desa Bojongmengger

Pada tahun 2010, anggota pengabdian membuat perahu pontoon sederhana yang dibuat dari bahan utama pipa PVC diameter 10 inci yang biasa penulis gunakan untuk berbagai keperluan di kolam ikan (empang). Keberadaan perahu PVC tersebut besar manfaatnya dirasakan untuk berbagai kegiatan di danau dan kolam, karena ukurannya yang kecil (tidak menghabiskan banyak tempat), ringan, memiliki daya apung yang baik, tidak mudah tenggelam, mudah dibuat, murah, mudah dalam pemeliharaan dan awet (sampai saat ini selama 10 tahun masih bisa digunakan dengan baik). Perahu PVC tersebut biasa digunakan sehari-hari untuk rekreasi, memancing ikan, memberi pakan ikan, olahraga air (dayung) dan permainan outbond. Berdasarkan pengalaman selama 10 tahun menjadi sarana angkut di air tenang, perahu PVC seperti ini telah dikembangkan menjadi sepeda air pipa PVC, yang bisa digunakan untuk pengunjung Situ Rancabunar nantinya.

Badan Usaha Milik Desa (BUMDES) adalah badan usaha yang seluruh atau sebagian besar modalnya dimiliki oleh desa melalui penyertaan secara langsung yang berasal dari kekayaan desa yang dipisahkan guna mengelola aset, jasa pelayanan dan usaha lainnya untuk kesejahteraan masyarakat desa (UU No. 6 tahun 2014). Peran BUMDES, yaitu: meningkatkan kesejahteraan masyarakat desa, membantu melakukan pengawasan terhadap pelaksanaan penyelenggaraan ekonomi desa, dan membantu pemerintahan desa dalam upaya mengembangkan sumber sumber potensi alam dan 
Membuat Sepeda Air Pipa Pvc Pada Bumdes Situ Rancabunar Desa Bojongmengger, Kecamatan Cijeungjing Kabupaten Ciamis

Zenal Abidin, Mujaddid Faruk

manusia di desa untuk dikembangkan menjadi sumber-sumber ekonomi (Sugiro, 2016). Keberadaan BUMDES Desa Bojongmengger sampai saat ini belum mampu memanfaatkan sumber-sumber alam dan manusia di Desa Bojongmengger secara optimal, salah satunya adalah potensi alam Situ Rancabunar yang masih belum dikembangkan.

\section{BAHAN DAN METODE}

Bahan yang digunakan dalam pengabdian ini berupa pipa PVC diameter 10 inci atau 8 inci (tergantung kebutuhan) sebanyak 1 lente merek apa saja, semakin kuat semakin baik. Sepeda mini second (misalnya sepeda BMX), pipa besi atau stainless steel diameter 1 inci (untuk rangka perahu) sebanyak 1 lente; dop penutup pipa diameter 10 inci sebanyak 4 buah; karet ban bekas lebar $10 \mathrm{~cm}$ sebanyak 10 lembar; lem tembak 8 lembar; cat besi 1 kaleng kecil; cat pilox 1 botol; karet tutup botol obat 2 buah; papan kayu $20 \mathrm{~cm}$ x $120 \mathrm{~cm}$ sebanyak 3 lembar; mur baut ukuran 8 sebanyak 6 buah; karet bahan sandal 1/4 lembar; dan tambang plastik.

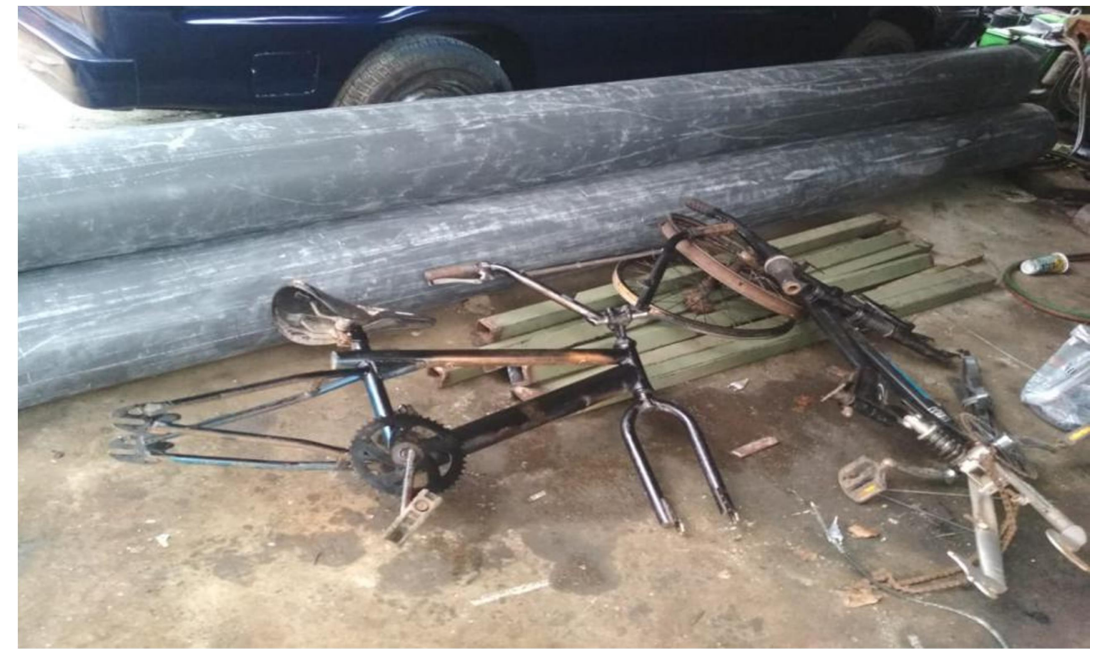

Gambar 2. Alat dan Bahan sepeda air

Metode pelaksanaan yang telah dilakukan dalam melaksanakan program pengabdian ini yaitu metode instruksional yang diikuti dengan praktek pembuatan sepeda air pipa PVC, penataan tempat wisata air, dan pelatihan manajemen operasional.

Program PKMS yang dikemas dalam kegiatan "Membuat sepeda air pipa PVC pada BUMDES Situ Rancabunar Desa Bojongmengger, Kecamatan Cijeungjing, Kabupaten Ciamis", dilakukan dalam beberapa tahapan, yaitu: tahap pertama berupa penyampaian informasi pengelolaan wisata air kepada para pengelola BUMDES, dan 
para pedagang melalui metode pembekalan dan isntruksional, tahap kedua pelatihan pembuatan sepeda air pipa $\mathrm{PVC}$, dan tahap ketiga pelatihan penataan tempat wisata.

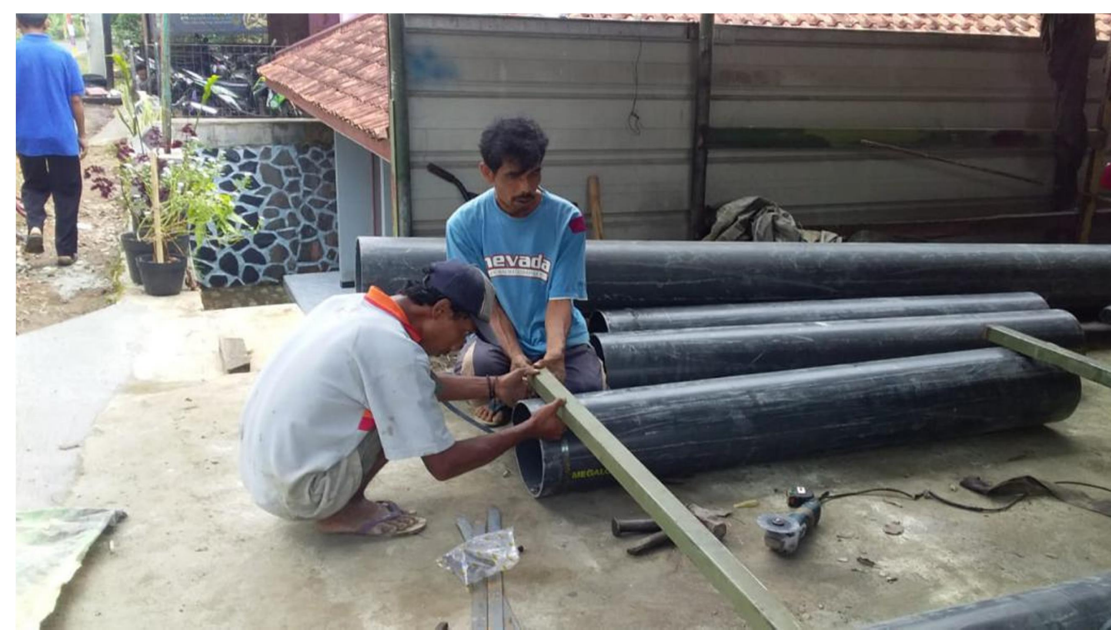

Gambar 3. Proses Perakitan sepeda air

Tahap I, kegiatan pada tahap ini berupa penyampaian informasi tentang wisata air (sosialisasi atau penyuluhan) kepada pengelola BUMDES dan para petugas di objek wisata Situ Rancabunar Desa Bojongmengger. Materi pertama yang diberikan meliputi: 1) materi umum yaitu optimalisasi pemanfaatan lahan, 2) materi khusus berupa pengetahuan wisata air. Materi kedua yang diberikan meliputi: 1) materi umum yaitu menumbuhkan jiwa kewirausahaan, 2) materi khusus berupa manajemen operasi untuk wisata air, dan 3) materi penunjang berupa analisis ekonomi dan pemasaran wisata air.

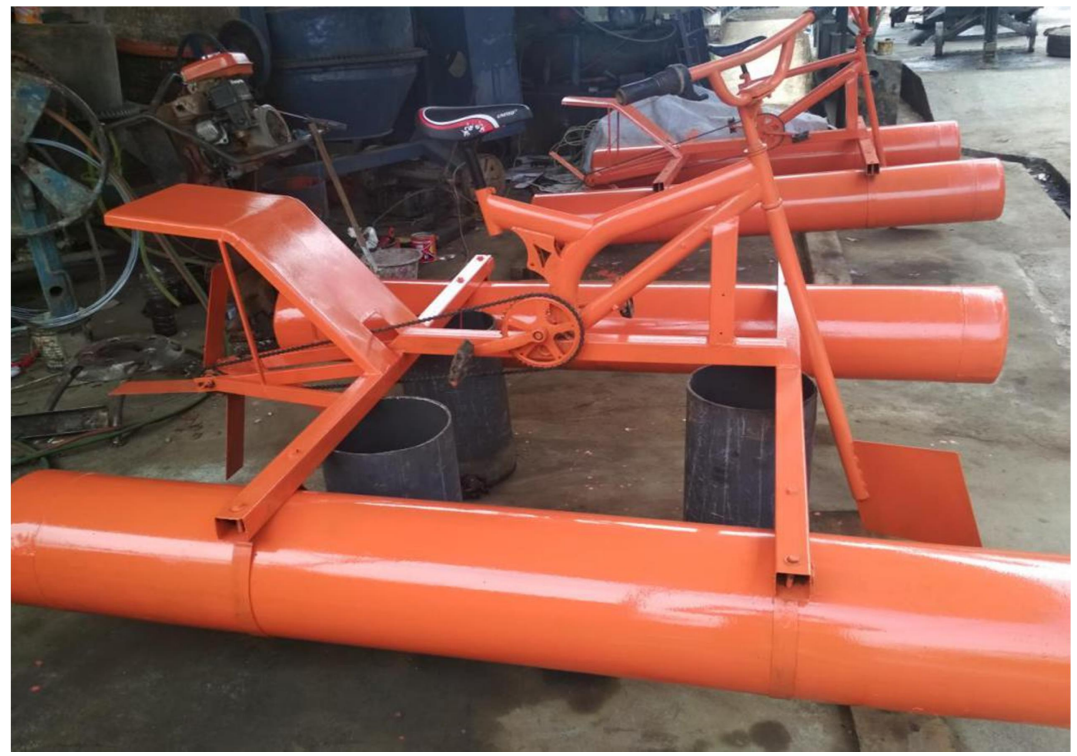

Gambar 4. Sepeda air sudah yang sudah jadi 
Membuat Sepeda Air Pipa Pvc Pada Bumdes Situ Rancabunar Desa Bojongmengger, Kecamatan Cijeungjing Kabupaten Ciamis

Zenal Abidin, Mujaddid Faruk

Tahap II, kegiatan yang telah dilaksanakan pada tahap ini yaitu pelatihan keterampilan pembuatan sepeda air pipa PVC. Materi yang diberikan meliputi: 1) Pembuatan desain, 2) Pemotongan bahan 3) Penyambungan, pengecatan, 4) Peluncuran, dan 5) Pengujian. Peserta pelatihan yaitu Pengelola BUMDES dan masyarakat sebanyak 10 orang.

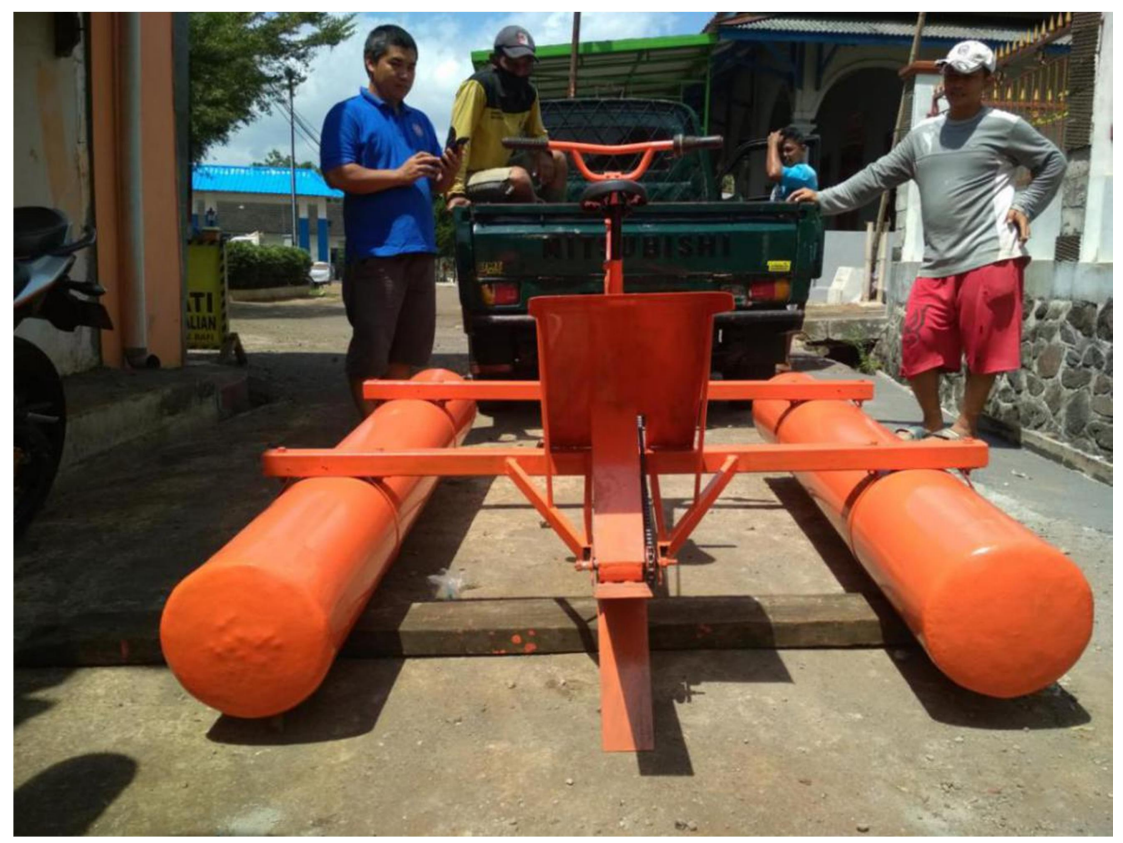

Gambar 5. Sepeda air diangkut menuju Situ Rancabunar

\section{HASIL DAN PEMBAHASAN}

Hasil yang dicapai adalah produk Sepeda Air dari pipa PVC yang bisa digunakan sebagai sarana wisata pada BUMDes Situ Rancabunar Desa Bojongmengger Kecamatan Cijeungjing Kabupaten Ciamis. Manfaat yang diperoleh bagi masyarakat adalah: sebelum ada pelatihan, pengelola BUMDES belum tahu bagaimana cara mengelola Situ Rancabunar agar dapat dijadikan arena wisata, maka setelah pelatihan ini mereka memiliki kesadaran dan pengetahuan tentangpengelolaan objek wisata (Tabel 1).

Tabel 1. Hasil yang Dicapai

\begin{tabular}{cllll}
\hline No & \multicolumn{1}{c}{ Kegiatan } & \multicolumn{1}{c}{ Target } & Capaian & Luaran \\
\hline 1. & Penyampaian informasi & Meningkatnya & Peningkatan & Modul \\
& tentang Wisata air berupa & pengetahuan Pengelola & pengetahuan & Manajemen \\
penyuluhan kepada & BUMDES dan Petugas & pengelola & Pariwisata \\
pengelola BUMDES dan & objek wisata memiiki & BUMDES & \\
para petugas di objek & pengetahuan tentang & & \\
& wisata Situ Rancabuna & pengelolaan objek wisata & & \\
\hline 2. & $\begin{array}{l}\text { Memberikan pelatihan } \\
\text { pembuatan sepeda air dari } \\
\text { pipa PVC }\end{array}$ & Tersedia produk sepeda & Tersedianya & Produk \\
& & sepeda air pipa & sepeda air \\
\hline
\end{tabular}




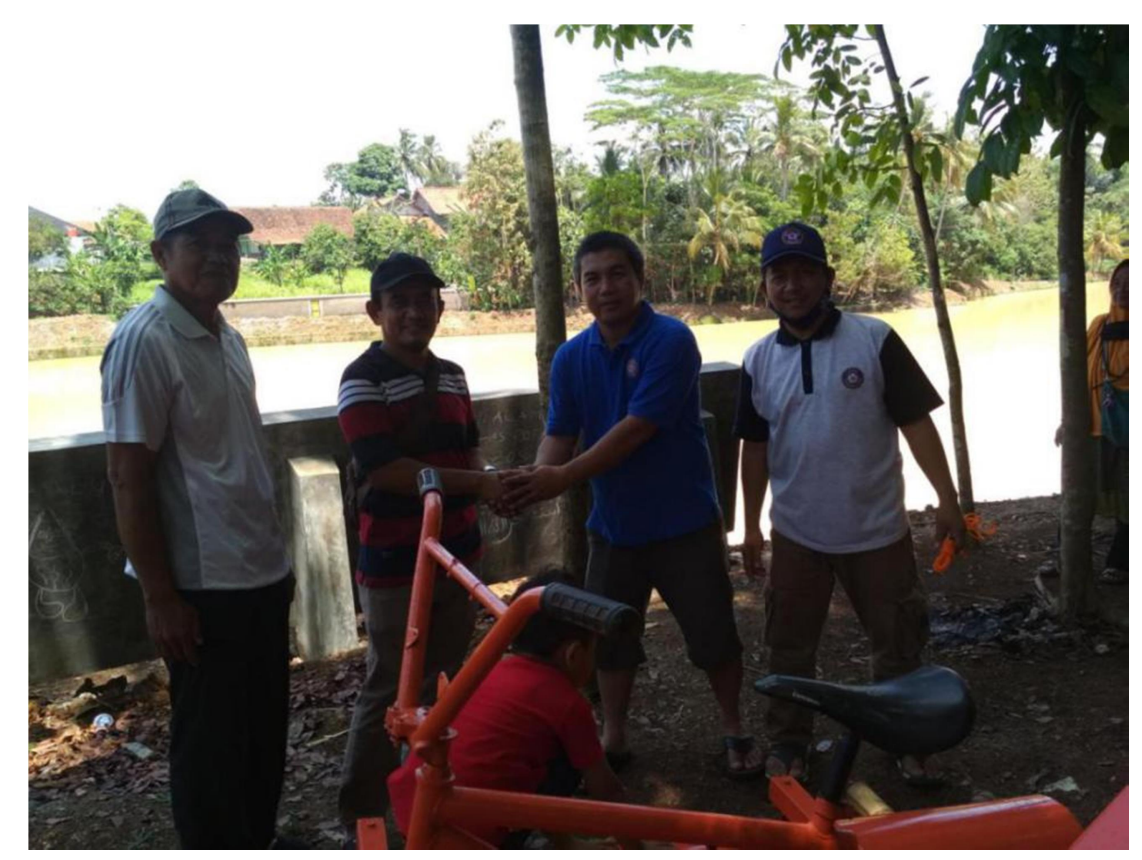

Gambar 6. Pelatihan Membuat sepeda air dan serah terima

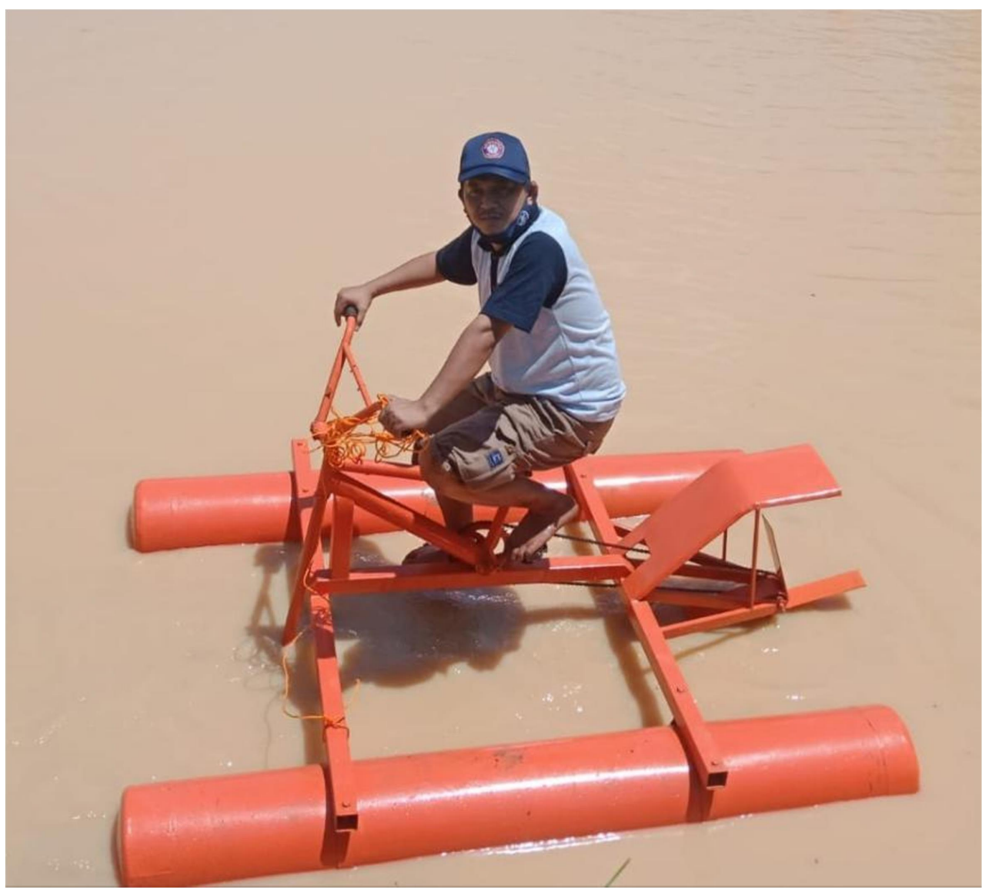

Gambar 7. Praktek penggunaan sepeda air dan penataan pariwisata

Tersedianya Sepeda air di Situ Rancabunar menyediakan sumber pendapatan baru dari jasa sewa, apalagi pada saat pandemi Covid 19 ini olahraga bersepeda menjadi pilihan banyak masyarakat, sehingga sepeda air menjadi alternatif sumber penghasilan baru BUMDES dari jasa sewa. 
Membuat Sepeda Air Pipa Pvc Pada Bumdes Situ Rancabunar Desa Bojongmengger, Kecamatan Cijeungjing Kabupaten Ciamis

Zenal Abidin, Mujaddid Faruk

\section{KESIMPULAN DAN SARAN}

Berdasarkan tahapan kegiatan yang telah dilaksanakan dalam program PKMS yang dikemas melalui "PKMS Membuat Sepeda Air Pipa PVC pada BUMDES Situ Rancabunar Desa Bojongmengger, Kecamatan Cijeungjing Kabupaten Ciamis”, maka dapat disimpulkan:

1. Setelah mengikuti pelatihan manajemen usaha dan penataan tempat wisata, para pengelola BUMDES: (a) melakukan bagaimana cara mengelola objek wisata secara optimal, (b) menganalisis usaha sewa sepeda air, (c) Tata letak (layout) wisata Situ Rancabunar.

2. Hasil yang dicapai dari kegiatan pelatihan membuat sepeda air, yaitu:

(a) Para pengelola usaha wisata Situ Rancabunar mengetahui desain produk untuk membuat sepeda air.

(b) Para pengrajin kayu mampu membuat sepeda air, dan manajemen usaha sewa produknya.

Saran dari program pengabdian ini adalah agar program PKMS ini berhasil dengan baik, maka perlu dukungan dari berbagai pihak.

\section{DAFTAR PUSTAKA}

Ginting, N. (2016). Strategi Pemasaran Untuk Meningkatkan Kunjungan Wisata DKI Jakarta. Jurnal Analisis Ekonomi Utama, 10(2): 89-98.

Maharani, D.P. (2014). Pengembangan Potensi Pariwisata Kabupaten Sumenep, Madura, Jawa Timur (Studi Kasus Pantai Lombang). Jurnal Politik Muda, 3(3): 412-421.

Soebagyo. (2012). Strategi Pengembangan Pariwisata di Indonesia. Jurnal Liquidity, 1(2): 153-158.

Ghani, Y.A. (2017). Pengembangan Sarana Prasarana Destinasi Pariwisata Berbasis Budaya di Jawa Barat. Jurnal Pariwisata, 4(1): 22-31. 